\title{
Sustaining growth in electronic manufacturing sector: lessons from Japanese mid-size EMS providers
}

\author{
Hui-Hong J.K. Li $^{\mathrm{a}}$, Kim Hua Tan ${ }^{\mathrm{b} *}$ and Atsunori Hida ${ }^{\mathrm{c}}$ \\ ${ }^{a}$ Centre for International Manufacturing, University of Cambridge, Mill Lane, Cambridge CB2 \\ IRX, UK; ${ }^{b}$ Nottingham University Business School, Jubilee Campus, Wollaton Road, \\ Nottingham NG8 1GL, UK; ${ }^{c} J S B$ Tech (Singapore) Private Limited, 41 Science Park Road, \\ \#04-02 Singapore Science Park II, Gemini, Singapore 117610
}

(Final version received January 2011)

\begin{abstract}
Many small and medium enterprises (SMEs) suffered badly from the recent economic crisis. However, a range of overseas Japanese SMEs in the electronic manufacturing sector seemed to do well, even achieving significant growth. Despite that, the electronic sector is in deep recession. Using three in-depth cases in the electronic manufacturing sector, this article discusses how successful overseas Japanese SMEs could achieve further growth and resilience to marketplace uncertainties. The findings suggest that firm growth could be achieved through (1) re-organising of manufacturing supply chain by reducing overseas Keiretsu obligations; (2) gaining negotiation powers to achieve economies of scale through acquisitions; and (3) adopting IT technology to achieve Lean and increase responsiveness to market changes. The implications of these findings for SMEs in other sectors are additionally explored.
\end{abstract}

Keywords: SME growth; EMS; Keiretsu; resilience

\section{Introduction}

Despite the recent economic crisis, the electronic manufacturing service (EMS) sector is still performing strongly. It is estimated that the EMS market will reach $\$ 387.42$ billion in 2013 (Frost and Sullivan 2007). EMS is a business targeting products that are difficult to differentiate through the production process (Kita 2001, Zhai et al. 2007). Thus, the profit margin of EMS providers is low (5-8\%) as compared to many other sectors. But, how can overseas Japanese small and medium enterprises (SMEs) in the EMS sector sustain growth and resilience in the present turbulent environment?

There is no easy answer to this question. Regardless of the level of focus, much of our understanding of firm growth draws upon the experience of western firms (Wernerfelt 1984, Hamel and Prahalad 1989, Melin 1992, Penrose 1995, Clark and Knowles 2003), or in the automotive/service sector. The emergence of Japanese EMS SME providers in global competition in the past few decades has significantly challenged traditional thinking on firm growth strategies. Despite the emergence of formidable low cost and aggressive manufacturers from Korea, Taiwan and China, Japanese SMEs remain a force to be reckoned with around the world (Bolton 1993, Cho et al. 1998, Choung et al. 2000, Chen and Toyama 2006). While there are a number of unique aspects associated with the

*Corresponding author. Email: kim.tan@nottingham.ac.uk 
Japanese manufacturing prowess such as just-in-time production, total quality management, and Keiretsu networks, little contemporary research or industrial studies are available to explain how midsize firms could build on these as a source of competitive advantage to gain rapid growth (Hobday 1995, Kim 1997, Mathews 2002, Leung and Yip 2003).

These issues may be seen to be of importance amid the rapid changing global environment of increased manufacturing operational cost in the Asia region, increased raw material cost, product/service cost reduction, industry/market consolidation and emergence of formidable low cost and aggressive manufacturers which are set to challenge Japan's strong position in the electronic manufacturing industry. The two main driving forces could be summarised as:

- The rise of Korean, Taiwanese and the Chinese manufacturers into the manufacturing arena. These newcomers are very aggressive, cost conscious, highly productive, very agile and lean (Kim 1997, Cho et al. 1998, Zhai et al. 2007).

- Large Japanese original equipment manufacturers (OEMs) are outsourcing to Korean, Taiwanese and Chinese companies in order to achieve lower cost relative to Japanese suppliers. The outsourcing of the large Japanese OEMs to contract manufacturers like Foxcon (world's largest Taiwanese EMS), Flextronic and SCI Sanmina has enabled these large contract manufacturers to select alternative non-Japanese suppliers in order to cut cost. Thus, the overseas Japanese EMS providers face intense competition in securing orders as the traditional Keiretsu system is no longer working.

Therefore, how can overseas Japanese midsize EMS providers survive in a highly shrinking market? Moreover, the product technology is changing and many disk drives (both magnetic and optical) are taken by semiconductor memory based, i.e. memory stick or thumb drives replacing optical drive, MP3/MP4 replacing CD and DVD drives. Furthermore, how midsize firms achieve economic of scale to gain negotiation power with the large OEM customers?

This article examines business models adopted by overseas Japanese midsize EMS providers in the electronic industry. It addresses two important research questions: (1) How do overseas Japanese midsize firms achieve growth and resilience despite market uncertainties; and (2) How can EMS growth models be adopted by SMEs in other sectors? These issues have considerable significance for the field of operations management and international business. In essence, international business pressures may provide a key channel to the evolution of midsize firms' supply chain strategy, and an understanding of the strategic implications of supply chain re-organisation is an important aspect of operations management (Ginsberg and Venkatraman 1985, Porter 1990, Baum and Haveman 1997).

There exist a number of compelling reasons why overseas Japanese midsize electronic firms are the focus of this study. First, Japanese firms are the leading electronic industry in Asia. Thus, no operations or strategic theory can claim to be complete without Japan. Second, as Japan shares many important common cultures with Korea, China and Taiwan, the Japanese experience can help shed light on future firm growth in Asia. Finally, as Japan is still a leading economy superpower, improved understanding of Japanese firms will have enormous practical implications for western firms that have business dealings in Japan. 
The article begins with a literature review on the growth of Japanese SMEs firms. Next, the three cases are described and the findings are discussed. Finally, the article closes with implications for future research and practice.

\section{EMS providers}

In light of globalisation and intense market competition, there is a tendency for firms to focus on core activities and to outsource those non-core activities in order to stay competitive. Furthermore in the electronic sector, product functionality has greatly improved whilst product lifecycles have typically shortened (Kita 2001). Consumers are increasingly demanding highly customised, high-quality product to be delivered quickly at a competitive price. The lifecycle for electronics goods such as digital cameras or mobile phones is generally around 3 months and prices can fluctuate wildly. In such environments, final assembly manufacturers (hereinafter referred to as the brand manufacturer) need speed to handle these short product lifecycles and to maintain competitive in the market (Kita 2001, Zhai et al. 2007). To achieve this, firms in the USA and Europe are focusing on their core competencies (core capabilities to provide unique value), while outsourcing processing and assembly to countries such as Taiwan and China (Cho 1998).

From the reviewed literature, it is obvious that an increasing proportion of end products are never touched by the company whose brand they bear. Instead, the manufacturing is contracted out to specialists, creating an industry known as electronics manufacturing services (EMS) (Kita 2001). These specialists are called EMS providers, whose customers are OEMs. Table 1 explains the scope of activities for various service providers in the electronic sectors.

Many electronic brand manufacturers develop functional relationships with EMS providers through supply chain management (SCM). EMS providers differ from conventional OEMs. OEMs are usually entrusted with just one specific aspect of the production process, with procurement of materials and components handled by the brand manufacturer (Kita 2001). The EMS provider, on the other hand, is entrusted with a comprehensive range of activities from design, trial manufacturing and procurement to

Table 1. Definitions of EMS, OEM and ODM.

\begin{tabular}{|c|c|}
\hline Terms & Scope of activities \\
\hline $\begin{array}{l}\text { Electronic manufacturing } \\
\text { service provider (EMS) }\end{array}$ & $\begin{array}{l}\text { Usually entrusted with everything from design, trial } \\
\text { manufacturing procurement, production and in some cases, } \\
\text { after sales services }\end{array}$ \\
\hline $\begin{array}{l}\text { Original equipment manufac- } \\
\text { turer (OEM) }\end{array}$ & $\begin{array}{l}\text { Usually entrusted with just one specific aspect of the produc- } \\
\text { tion process, with procurement of materials and compo- } \\
\text { nents handled by the brand manufacturer }\end{array}$ \\
\hline $\begin{array}{l}\text { Original design manufacturer } \\
\text { (ODM) }\end{array}$ & $\begin{array}{l}\text { Usually entrusted with design as well as build products or } \\
\text { components for sale to a second company that retail under } \\
\text { the brand name of the second company. The crucial } \\
\text { difference is that an OEM manufactures, while an ODM } \\
\text { designs and manufactures }\end{array}$ \\
\hline
\end{tabular}

Source: Adapted from Kita (2001) and Zhai et al. (2007). 


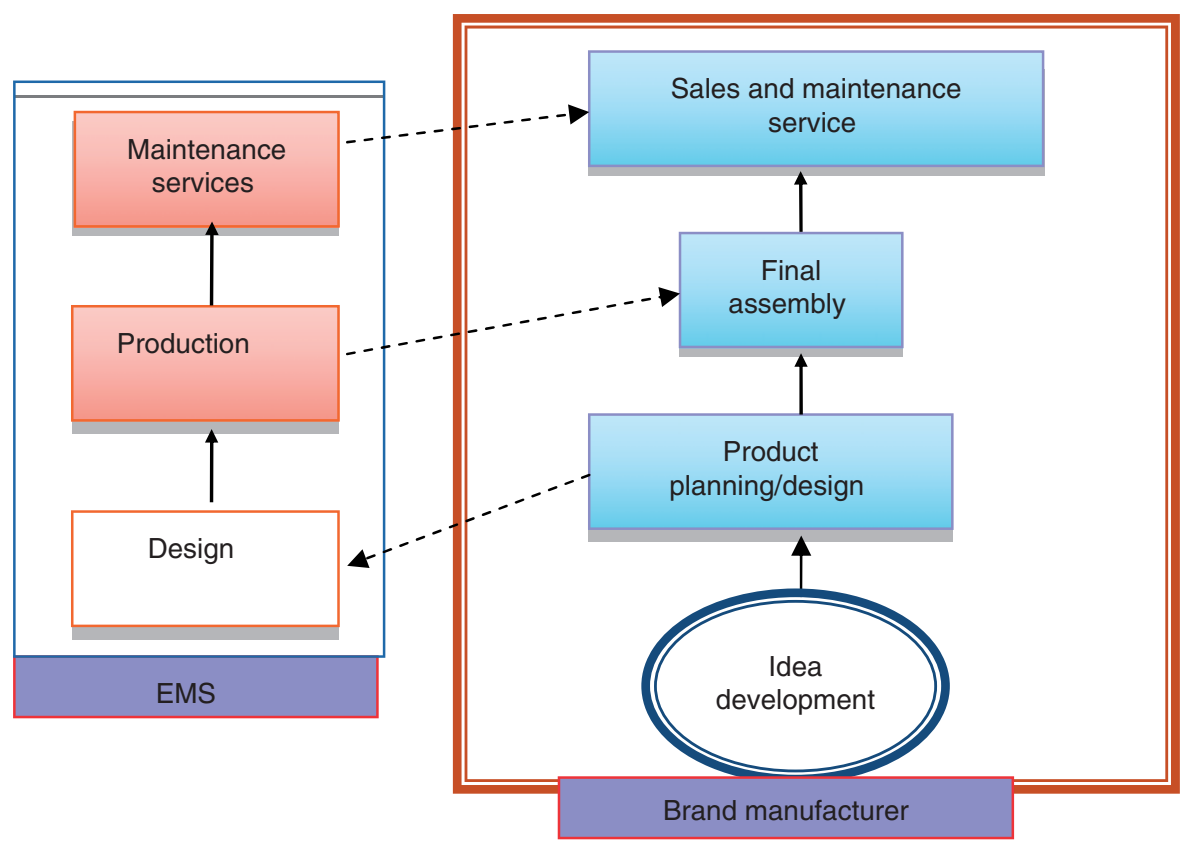

Figure 1. The relationship between EMS and the brand manufacturer.

production and, in some cases, after sales services (Kita 2001, Leung and Yip 2003). The EMS provider can be an independent corporation that does not have its own brand and is not dependent on a single client, but has a wide range of customers (Kita 2001). Figure 1 provides an illustration of EMS relationship with the brand manufacturer. It shows the high level of information exchange and integration at each stage of product development (including after sale services) between the brand manufacturer and EMS.

The EMS provider can use reliable software such as electronic data interchange or Internet to exchange order and technical information with the brand manufacturer. This informational advantage bestowed by interfirm ties can be particularly valuable in a global setting (Gulati 1999). Moreover, the use of SCM approaches can provide a number of benefits. First, it can shorten the lead-time from procurement of raw materials and components to production (Kim 1997). Second, the EMS provider can establish production and distribution centres around the world to help lessen the client's inventory risks (Kita 2001). Third, by risk spreading over a number of clients, EMS can smoothen orders and optimise production (Deguchi 1996).

\section{SME growth and resilience models}

A growth strategy for SME firms is necessary due to their relatively limited resources, technology, finance and geographic span reach. SMEs often focus in niche market segments, are highly competitive, responsive and thrive within their specific industry. Prashantham (2008) mentions that SMEs are able to form and take advantage of ties with local subsidiaries of foreign multinational corporations (MNCs). However, forming 


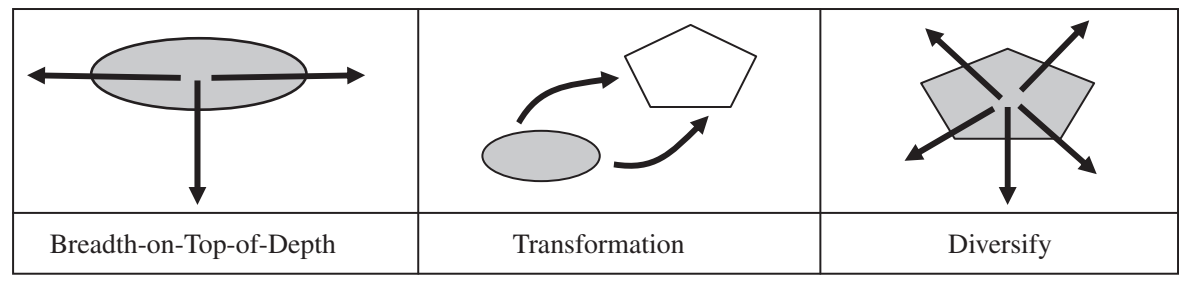

Figure 2. Three perspectives for business growth model.

(C) Inderscience Publishers (first published in Li and Tan 2004).

relations with MNC subsidiaries was relatively difficult if there is lack of trust (Prashantham and McNaughton 2006). Local MNC ties are potentially valuable sources for SMEs' technological and market knowledge, and could lead to important network relationships in international markets. While previous literatures (Sarkar et al. 2001) investigated the differences between small and large firms, the focus here is on the overseas Japanese SMEs and local MNC subsidiaries as network partners in the electronic manufacturing sector.

According to $\mathrm{Li}$ and Tan (2004), there are three major theoretical perspectives to growth each leading to particular strategic choice (Figure 2). First, in the breadth-ontop-of-depth (BTD) perspective, firms seek to balance technical depth with product breadth. The key reason for the selection of such an approach is that by increasing their knowledge and exposure to related areas, they create the possibility of developing additional areas of expertise. For example, having established its reputation in the electronic industry, Samsung expanded its operations into a variety of industries ranging from sugar and flour refining to insurance, medical care and news media ( $\mathrm{Li}$ and Tan 2004). In the growth literature, this perspective can be viewed as an attempt by top managers to fully utilise the firm's resources. Firms grow into new areas when there is an excess in capacity in under-utilised resources. The internally generated nature of such growth is thus called 'generic' expansion. However, there is a limit to the growth of the firm as no firm is capable of generating internally driven expansion indefinitely. In short, this perspective articulates the incremental process of the genetic expansion strategy, and suggests that the prerequisites for such growth are a firm's managerial and organisational capabilities (Peng 1997).

The second theoretical perspective, the transformation perspective, suggests firms think ahead, and to some degree act ahead of the stage they are currently occupying. They not only demonstrate their willingness to assume the size/market they are seeking, but also their readiness to do so. Just as other midsize firms began thinking about expansion, they need to begin doing some of the things MNCs do while they are still a midsize firm. The transformation view is closer to the transaction cost perspective, which suggests that the full employment of under-utilised resources often cannot be achieved by selling or leasing out the excess capacity to other firms, but requires an expansion of the boundaries of the firm (Penrose 1995). Thus, firms have to engage in acquisitions of other firms in order to achieve such growth. For acquisitions to take place successfully, there must be efficient strategic factors such as financial markets so that firm ownership and associated property rights can be smoothly transferred (Jensen and Ruback 1983).

The third perspective is diversify. In this strategy, firms expand their product range and production capabilities based on their core competence. Samsung and Acer expanded their 
Table 2. Growth and strategic choice.

\begin{tabular}{|c|c|c|}
\hline $\begin{array}{l}\text { Growth } \\
\text { perspective }\end{array}$ & $\begin{array}{l}\text { Strategic } \\
\text { choice }\end{array}$ & Mode of organising \\
\hline BTD & Generic expansion & Achieving expansion through supply chain re-organisation \\
\hline Transformation & Acquisitions & Gaining bigger bargaining power through acquisition \\
\hline Diversify & Networks & Gaining higher responsiveness to market through IT adoption \\
\hline
\end{tabular}

operations by capitalising on their earlier BTD knowledge and experience to move up along the product value chains. Acer's CEO Stan Shih calls this re-orientation his 'smiling curve' (Bartlett and Ghoshal 2000). Succeeding in component production requires strong technology and enough manufacturing skill to produce economies of scale. Succeeding in distribution required a solid brand, established channels and effective logistics. The previous two perspectives promote growth through genetic expansion or acquisitions, but this perspective emphasises on a variety of interorganisational relationships such as strategic alliances and joint ventures in order to achieve growth (Kale et al. 2000, Sarkar et al. 2001, Coveillo 2006). This strategy of growth does not reflects the firm's inability to possess the necessary resources to undertake generic expansion or to acquire other firms. Rather, it represents the firm's efforts to gain access to complementary assets and to reduce environmental uncertainties. While mutual trust is needed to coordinate inter-partner cooperation, resource dependency and complementary capabilities are also necessary (Salancik and Pfeffer 1978).

Taken together, the streams of research reviewed above, permeated by Peng (1997), lead to a 'three strategic choice' model summarised in Table 2. This model suggests firms have three basic strategic choices for growth: (1) to undertake generic expansion; (2) to conduct acquisitions; and (3) to develop networks of firms.

For SME in the EMS sector, each of the growth perspective entails a different approach in sourcing configuration. Knudsen and Servais (2007) identify four different types of international sourcing configuration based on two dimensions of the level of international sourcing and international selling activities. Locals are ones with a low level of international engagement and rely on local customers and local suppliers. The global are ones with high involvement in both international sourcing and international selling.

\subsection{Resilience models}

Traditionally, resilience is viewed as the qualities that enable individual, community or firm to cope with, adapt to and recover from a disaster event (Riolli and Savicki 2003, McManus et al. 2007). As compared to growth models, there is little literature on SME resilience. Hamel and Valikangas (2003) point out four challenges: (1) cognitive; (2) strategic; (3) political; and (4) ideological, that a firm must overcome in order to achieve strategic resilience; however, this was mainly targeted at MNCs. Other literature on resilience tends to focus on supply chains (Hong and Choi 2002, Christopher and Peck 2004, Ponomarov and Holcomb 2009); disaster (Rutter 1993, Paton 1999, Mitroff and Alpasan 2003); or on a specific strategy, i.e. innovation (Reinmoeller and van Baardwijk 2005). 
Based upon the reviewed literature, we conceptualise three basic characteristics of resilience which are applicable to SME, namely:

- Adjustment capacity - stresses the acceptance of change and tries to create a system that is capable of adapting to new conditions (or returning to original states) (Rutter 1993, Coutu 2002, Hamel and Valikangas 2003, McManus et al. 2007).

- Process capability - argues for the ability to reinvent existing processes or seek external cooperation to overcome barriers to change. This characteristic is also termed as 'self-renew' achieved through innovation (Hong and Choi 2002, Christopher and Peck 2004, Reinmoeller and van Baardwijk 2005, Sheffi and Rice 2005).

- Risk proactive - points out that leaders should take risks and renew their strategies before being forced to by an impending performance crisis (Pearson and Mitroff 1993, Starr et al. 2003, Sheffi 2006, 2007).

Thus, we define SME resilience as the capability to self-renew over time, to maintain status-quo or move to a new desirable state after (or before) being disturbed.

In the following section, we describe the research design used to study how overseas Japanese SMEs can achieve growth and resilience to uncertainties, in a fast moving technology-driven industry. In particular, we examine how a number of Japanese SMEs in the electronic sector achieve significant growth in looming recession.

\section{Research design and methodology}

The study of technology-driven SMEs has relatively little theoretical background. Case study research is especially appropriate for studying the growth and development patterns of SMEs. Many researchers (Eisenhardt 1989, Meredith 1998, McDermott 1999) point out the strengths of case research, especially for allowing researchers to: (1) document a phenomenon within its organisation context such as growth; (2) explore the boundaries of a phenomenon such as resilience to uncertainties; and (3) integrate information from multiple sources.

\subsection{Participating firms}

Three cases of Japanese EMS SMEs (located in overseas) were selected. These cases have been selected for a number of reasons. First, they provide a regional coverage. Second, they include some of the dynamic experiences of growth and competitiveness in local and global markets by Far East MNCs in recent years. Third, these cases indicate both diverse growth paths as well as reflect common issues regarding the technology driven firms. The variety in the cases was a deliberate research design strategy chosen to increase the external validity of the study, and to assure that the findings were generalisable and not specific to any one type of manufacturing process or market (Yin 1994). Synopsis of the three firms are provided in Table 3 below.

\subsection{Longitudinal case method}

A longitudinal case study approach (over 6 years, over 10 visits per year per case) was adopted. One of the authors in this article has a good contact within the three firms, 
Table 3. Case background.

\begin{tabular}{lc}
\hline Case & Primary service and background \\
\hline A - Precision motor & Testing, manufacturing, design and assembly. Established in \\
manufacturer & 1970 s and 91\% of sales to Japanese clients \\
B - Flexible printed circuit & Testing, manufacturing, design and assembly. Established in \\
(FPC) board manufacturer & 1970 s and $83 \%$ of sales to Japanese clients \\
C - Printed circuit board & Testing, design and assembly. Established in 1990s and 86\% \\
(PCB) assembler & of sales to Japanese clients \\
\hline
\end{tabular}

and thus able to get permission to gain access to persons who are best informed about the data being researched. For each case, senior management (including CEO, Vice Presidents of R\&D, Operations and Marketing), and project managers were interviewed. Using multiple interviewees brought a richer portrait of each case (Yin 1994), and also aided in mitigating bias in historical data interpretation (recollection). For example, interviewees may not recall important events and, even if they do, their recollection may be subject to bias. A particular problem is post-rationalisation, the interpretation of events in a different manner than they would have at the time. For example, the respondent may place interpretations on events, or justify decisions with arguments or knowledge that was not available at the time (Voss et al. 2002).

To avoid researcher bias, visits to case study sites and interviews were conducted in pairs. All interviewers were tape recorded. Each can then review what is observed by the other. Two of the researchers are fluent in Japanese, thus, were able to capture the essence of the conversation perfectly and reduce information lost in interpretation. In addition, secondary data (annual report, news cuttings) and interviews with their suppliers were also conducted to confirm the findings/interpretation. Through triangulation with multiple means of data collection, the validity could be increased further.

\subsection{Data analysis}

In reviewing the EMS SME business growth models, the objective was to understand: (1) their main characteristics; (2) strategies of co-operation that raise efficiency and upgrade skills and technologies; and (3) the organisational and technical learning strategies that furthered the growth of the customer base.

To uncover and examine the key themes in the data, an approach out-lined by Miles and Huberman (1984), and Meredith (1998) was used. In particular, a cross case method for exploring and describing themes was adopted which allows for the understanding of the phenomena beyond each individual firm's context and to increase the generalisability of the observations (Eisenhardt 1989, McDermott 1999).

An iterative approach to travel back and forth between data, literature and emerging theory was used to solicit the themes. Each firm's history was first constructed, thus generating a series of 'minicases' (Eisenhardt 1989). The interview data were transcribed and a representative set of the interviews was used to establish common themes emerging from the data. Then patterns of the growth were sought. For the purpose of this study, the growth construct was measured on assets and sales (Lu and Beamish 2001). Each case was then reviewed to see if the pattern was confirmed, rejected or ambiguous, with appropriate 
theoretical literature consulted. The three main themes emerged from the data analysis were: supply chain re-organisation (Keiretsu), acquisitions and responsiveness.

\subsection{A brief description of the three case studies}

\subsubsection{Case $A$}

Case A is a Japanese SME manufacturer, specialising in manufacturing high precision motors electronic module used in magnetic hard disk drives and optical disk drives such as DVD and CD drives for computers and consumer products (e.g. CD, DVD, camcorder, etc.). It is an established company supplying motor units to the key OEM players (e.g. Hitachi, Pioneer, Samsung, LG, TEAC, JVC, Panasonic, Sony and Philips). Case A has a number of manufacturing plants in ASEAN.

4.4.1.1 Acquisition. Most OEMs tend to pitch EMS providers against each other over prices. Case A realises controlling a bigger share in the market place will help its bargaining power. Case A consequently began to acquire its losing competitors. Five years ago, Case A aggressively took over two major competitors, i.e. Sankyo Motor Co. and Japan Servo Motor Co. to increase its size and with strategy intended to control a major share in the hard disk drive segment in the region. In addition to gaining a majority market share through the acquisition of the two major competitors, additional South East Asia plants and design capabilities of these firms were also integrated into Case A company portfolios. Case A also took over another Singaporean EMS provider (Brilliant Co.), which specialised in manufacturing and assembling hard disk components (manufacturing plants located in Batam, Indonesia, Suzhou, China and Malaysia). Through this rapid sequence of acquisitions, Case A gained widespread technical expertise associated with high-precision processing, testing and measuring, and press technology as its group assets.

4.4.1.2 Responsiveness. After acquiring companies, it focuses on integrating and consolidating factories to slimming the manufacturing supply chain. It re-organises factories and chooses specific suppliers in which to develop a partnership with and collaborate. It believes that by doing so, it increases its negotiation power to its customers and reduces its cost by selecting efficient suppliers and creating economic of scale.

4.4.1.3 Keiretsu obligation. Case A management also utilised the local (non-Japanese) suppliers to elude the recent local cost pressure. To stay competitive (lower production cost), Case A decided to break off from the overseas Japanese Keiretsu supply network by not sticking to its Japanese suppliers. Moreover, with its bigger market share and bargaining power, Case A has now attracted significant western orders. Its supplier selection criteria has now shifted from traditional relationship based to performance based.

\subsubsection{Case B}

Company B is a module manufacturer for a flexible printed circuit (FPC) board used in the hard disk drive industry for both computer and consumers industry. Flexible printed circuit boards (PCBs) are superior to traditional rigid PCB as it can be bent and folded, 
and is critical in enabling electronic circuits to be squeezed into smaller and light weight handheld electronic products. Case B has manufacturing plants in Japan and ASEAN region serving OEM customers such as Hitachi, LG, Toshiba, TEAC, SONY, Onkyo, Yamaha, Canon and Epson.

4.4.2.1 Acquisition. To gain better bargaining power in light of the break off of Keiretsu system, Case B has been aggressively expanding for the past 5 years in the region. The expansion included factories in Batam, Kuala Lumpur, Shenzhen, Suzhou and Vietnam. Most of these factories were obtained through acquisition of its smaller competitors as well as the non-core business unit of the OEMs. In addition to its acquisitions in late 2007, Case B also built new plants in Hochimin and Hanoi to tap into the aggressive expansion of major Japanese MNCs in Vietnam.

4.4.2.2 Responsiveness. With various factories in different cities (and inheriting the 'existing' practices from the acquired firms), Case B's management faced a number of challenges in productivity and delivery performance. To overcome this, Case B introduced Lean management to its factories and adopted ERP and MRP to standardise order taking and production scheduling. These initiatives have helped Case B to achieve greater economies of scale and to sustain bargaining power in the market place.

4.4.2.3 Keiretsu obligation. Many Japanese OEM manufacturers are outsourcing their products through ODM to Korean, Taiwanese and Chinese manufacturers. Indirectly, this practice challenges the traditional Keiretsu system. Moreover, the cost pressure on hightech commodity products in recent years plus the increase in raw material price of making FPC has triggered OEMs to opt for open tender. This has forced Case B to re-organise its supply chain and to look for non-Japanese second and third tier suppliers, breaking traditional supply networks and ending years of Keiretsu system.

\subsubsection{Case $C$}

Case $\mathrm{C}$ is a Japanese SME specialising in full scale OEM point-of-sale printers assembling and testing. It has assembled plants in Batam, Bangkok, Suzhou, Philippine, Japan and Ho-chimin. The key OEM customers in the industry are Sony, Hitachi, Pioneer, TEAC, JVC, Panasonic and Philips.

4.4.3.1 Acquisition. In order to spread the risk and ensure a continuity in assembly orders, Case $\mathrm{C}$ aggressively acquired smaller competitors within its niche segment in ASEAN. With a bigger market share, Case $\mathrm{C}$ is able to negotiate with its OEMs to smooth out the fluctuation of incoming orders. Case $\mathrm{C}$ focuses on acquiring point-of-sales printer business from various smaller Japanese printer's component and module manufacturers with the ultimate objective to vertically integrate them to provide a complete solution to brand owners outsourcing from Japan, EU and the USA.

4.4.3.2 Responsiveness. Case $\mathrm{C}$ started by providing a labour intensive product assembly service for its Japanese customers for products such as rigid PCBs, flexible PCBs, printers, 
touch-screen point-of-sales and cables. At the same time, the company started to tap into production activities that possessed a low-entry barrier, but generated higher profit margins than the labour intensive productions, for example plastic inject moulding. Whilst entering these new areas of production, Case $\mathrm{C}$ tried to win new orders from its existing customers, because it was felt that it would then be much easier to expand its operation. Due to specialisation, the established core manufacturing capabilities were continuously improved (Kaizen), standardised and transferred to various factories in the region to gain efficiency and maximise productivity. The company's core manufacturing process capability can be clearly observed and benefited by its customers when compared to its competitors. In addition, Case $\mathrm{C}$ aggressively implemented Lean and standardise business operations through ERP and vendor management system investment. The information technology (IT) investment helped to reduce product volume fluctuation, lower inventory cost and reduce the lead time from order to delivery.

4.4.3.3 Keiretsu obligation. Instead of purchasing goods from the Keiretsu network, Case $\mathrm{C}$ decided to gradually break off from it in favour of its first and second tier local suppliers. This is because, due to rapid expansion through acquisition, it is hard to find a local Keiretsu network to support its operations. Moreover, the Japanese OEMs have now been openly giving orders to Koreans, Taiwanese or Chinese assemblers. The shift in the supply chain practice has brought Case $\mathrm{C}$ many benefits. For example, in the recent financial tsunami, many SMEs have collapsed due to shrinking orders from Japanese OEMs. Consequently, Case $\mathrm{C}$ has seen a growth in revenue mainly by taking the opportunity to acquire several small business units owned by large MNCs who were forced by the economic conditions to restructure and shake off its non-core business units (in order to re-align its assets to new corporate strategy). These business units were acquired at a very minimum cost, but they will potentially contribute to forge a formidable core capability of Case $\mathrm{C}$ in the future.

\section{Results and discussion}

From research analysis of the case studies, three main themes emerged. These comprised: supply chain re-organisation (Keiretsu), acquisitions and responsiveness, which is in line with SME growth study in prior literature (Kim 1997, Lu and Beamish 2001, Sapienza et al. 2006). In the following paragraphs, each theme will be explored in more in-depth.

\subsection{Achieving better supply chain advantage by breaking off Keiretsu system}

Going forward, EMS providers need to offer differentiated services to OEMs, while simultaneously retaining the current level of services. Noting that, in particular, EMS providers offering design services in niche segments can increase revenues and profits substantially. Moreover, EMS providers are expected to benefit from the growth potential within manufacturing supply chain related lean and responsive operations, where more firms are adopting outsourcing practices to reduce operating costs.

All the three cases achieved better supply chain advantage by breaking off from the traditional Keiretsu system. Though, in all cases, it was partly the OEMs move to outsource to cheaper foreign manufacturers like Koreans, Taiwanese or Chinese that triggered the SMEs to reconsider its Keiretsu obligations. Nonetheless, the cases showed 
that by letting go of the 'traditional' ties, the three SMEs were able to gain better supply chain advantages. Furthermore, the current economic turbulence, shorter product lifecycle and rapid price competition demands a 'wider' and responsive supply network in order to adapt to demand changes, spread the risks and achieve economies of scales.

Moreover, the increasing market pressures forced the firms to move away from 'relationship' practices to developing a more disciplined supply relationship approach (Lu and Beamish 2001, Sapienza et al. 2006). For example, Case C let go its traditional Keiretsu obligation to compete in the open market, and Case B augmented its learning from OEMs by investing in standardised manufacturing processes. Clearly, the ability of the three SMEs to change rapidly and respond effectively to external forces is a characteristic of business resilience. Particularly their capabilities to reinvent existing processes and seek external cooperation to develop multiple sources of competitive advantage.

\subsection{Acquisitions to gain bargaining power}

The question of interest here is how firms grow in an often specialised niche segment and expand the product range within this segment. In all three cases, the Japanese EMS SME opted to acquire smaller competitors to component suppliers within its niche segment in order to achieve a superior market positioning. For example, Case B acquired the OEMs non-core business units to reduce the number of competitors in the market segment and to enhance its bargaining power.

The EMS sector is fragmented with many small SME providers competing for orders. To sustain and achieve growth, most EMS providers need a certain amount of volume in order to compete successfully and to develop capabilities. Moreover, OEMs prefer to deal with larger EMS providers in order to reduce delivery and asset investment risks. This forces SMEs to grow in order to gain economies of scale and gain stronger negotiation power within the market segment. The situation is compounded by the rise of aggressive Korean, Taiwanese and more recently Chinese competitors offering lower cost and highly responsiveness to OEMs' needs. The CEO in Case C likened it to the phrase, 'you grow or you are dead!' The three cases indicate the importance of risk proactive in achieving resilience, i.e. leaders renew firms' strategies through acquisitions to battle future uncertainties as well as to gain competitive advantages.

The ASEAN monetary crises a decade ago and the current global financial crises have forced many players within the electronic industry to consolidate. Equipped with the experiences gained through previous crises, many well-positioned Japanese SMEs are taking advantage of this to acquire weaker competitors and suppliers in order to grow. All three SMEs ensured resilience by realising that staff and responsive operations were their major assets, and to exploit the best practices of all acquired firms. These growing manufacturing companies will then be in a better position to emerge as potential leaders in their respective market segments when the market recovers.

\subsection{Achieving responsiveness through IT investment}

Although the fundamental task for EMS providers is to manufacture products for their OEM customers, the services relating to these products are also a major deliverable. As EMS companies combine supply chain services (including component sourcing, 
production, logistics and design) with the products they produce, it is critically important to have an efficient yet agile/responsive operations.

'One of the reasons smaller competitors were acquired by my firm is their lack of operations competitiveness and scale', the CEO of Case A commented. Thus, as Case A grew and obtained multiple factory sites, it found that its operations became inefficient and less responsive to market demands. To overcome this, Case A invested heavily in IT systems such as MRP, ERP and vendor management systems in order to standardise and monitor its operations more effectively.

Also, as large Japanese MNCs are breaking old traditional Kieretsu links in favour of Korean, Taiwanese and Chinese suppliers offering lower price and faster response speed, all three cases can no longer depended solely on their Keiretsu network. Instead, they have to rely on their operations management systems and strategic positioning to increase bargaining power.

Accepting the inevitability of change and to create a supply network system that is capable of adapting to a new environment is a primary characteristic of business resilience. The cases are classical examples of resilience and show how SMEs adapt as well as reinvent existing processes in order to develop new competitive advantages when faced with a crisis.

\section{Conclusions}

We have conducted primary research over the past 6 years to focus on 15 high growth Japanese manufacturing SMEs. All of these companies are listed in the Tokyo stock exchange. The three cases selected represent three groups of chosen growth paths that the successful Japanese SMEs grow in the turbulent global financial crises time. More importantly, the cases have shown the different ways in which resilient SMEs can be developed to face severe business uncertainties.

Many SMEs in the EMS sector foreclosed in light of the recent financial crisis. However, a group of Japanese SMEs in EMS have demonstrated strong resilience by taking advantage of the crisis to gain significant growth. This research identified three resilient models used by EMS SMEs, which could be of significant use to SMEs in other sectors.

- SCM reoganisation to sustain growth - Due to globalisation, SCM now plays an important role in enhancing SME performance. However, research in SCM and operation strategies predominantly focuses on large firms and developed markets. There is limited understanding of how SMEs develop international supply chain activities strategically to support firm performance and competitive advantages. The findings from this research addresses this gap by identifying some key issues concerning the extent of SME international supply chain involvement and the trend of Keiretsu meltdown in Japanese SMEs.

- Acquisition - Although acquisition has been noted as one of the key strategies for SME growth, there is little empirical work in this aspect. This research shows that acquisition could be more beneficial than organic growth, especially in a fast moving industry.

- Responsiveness - Literature is abound with panacea on how to sustain growth. For SMEs with limited resources, it is hard to adopt what has been the 'solution' for MNCs. This research shows that effective operations and IT investment are vital for firm improvement. Focusing on the basics like standardising ordering 
and purchasing processes, vendor management systems and information sharing can increase firms' agility, even in a highly turbulent and competitive industry.

The cases presented showed that SME business resilience can appear in many forms. However, a resilient SME can adapt and develop new opportunities, and raise competitiveness at firm levels. Most interviewees mentioned that they had not been conscious of the fact they were successful in showing resilience. In hindsight, they have shown that SMEs can be resilient at any time, i.e. to rebound and learn from adversity; to adapt; to take risks; and self-renew. In other words, the ability of a firm to adhere to what they know best and continuously adapt to gain a bigger market share is required to maintain competitiveness.

The EMS sector is always the first to bear the brunt of economic downturn. Yet, the resilient models used by the EMS SMEs have not been properly researched. This research is the first attempt to shed light on this aspect. Nonetheless, the limitation in this study is that internationalisation strategy and the role of supply chain involvement for EMS SMEs is likely to be different in other markets. Hence, there is a need for more research to investigate the impact of international supply chain activities on SME firms. This article calls for more SME-oriented conceptual and empirical research that links international supply chain strategy with international entrepreneurships and internationalisation.

Based on a sample of 15 firms, this study is small. As in any qualitative study, the results, while rich in individual in-depth cases, are not statistically significant. Moreover, the analyses was based on retrospective data which may have introduced an additional source of bias resulting from retrospective sense making on the part of the informants. Attempts were made to limit this bias by using multiple informants, triangulation and performing longitudinal studies for each firm, in addition to data from the company website and independent publications.

Nevertheless, this study does represent an initial step in empirically examining the growth strategies of Japanese EMS SMEs. The three cases and 6-year longitudinal study ensure a rich database and external validity of the research, which enables the findings to be generalisable to SMEs in other non-technological industries. A better understanding of the current development of Japanese SME behaviour will not only help in collaborating with western firms, but will also greatly enrich the theory of the SME growth and resilience models.

\section{References}

Bartlett, C.A. and Ghoshal, S., 2000. Going global: lessons from late movers. Harvard Business Review, March-April, 78 (2), 132-143.

Baum, J.A.C. and Haveman, H.A., 1997. Love thy neighbor? Differentiation and agglomerations in the Manhattan Hotel Industry, 1898-1990. Administrative Science Quarterly, 42, 304-338.

Bolton, M., 1993. Imitation versus innovation: lessons to be learned from the Japanese. Organization Dynamics, 21 (3), 30-46.

Chen, D.C. and Toyama, R.T., 2006. Catch up of semiconductor latecomers in China. International Journal of Emerging Markets, 1 (3), 247-261.

Cho, D.S., Kim, D.J., and Rhee, D.K., 1998. Latecomer strategies: evidence from the semiconductor industry in Japan and Korea. Organization Science, 9 (4), 489-505. 
Choung, J.Y., et al., 2000. Transition of latecomer firms from technology users to technology generators: Korean semiconductor firms. World Development, 28 (5), 969-982.

Christopher, M. and Peck, H., 2004. Building the resilient supply chain. International Journal of Logistics Management, 15 (2), 1-19.

Clark, T. and Knowles, L.L., 2003. Global myopia: globalization theory in international business. Journal of International Management, 9, 361-372.

Coutu, D.L., 2002. How resilience works. Harvard Business Review, 80, 47-55.

Coviello, N.E., 2006. Network dynamics of international new ventures. Journal of International Business Studies, 37, 713-731.

Deguchi, H., 1996. Open sourcing that promotes autonomous dispersion. Practice of outsourcing and organizational evolution. London: Diamond Publishing Company, 208-209.

Eisenhardt, K.M., 1989. Building theories from case study research. Academy of Management Review, 14 (4), 532-550.

Frost and Sullivan, 2007. Electronics manufacturing services markets in southeast Asia. Market Engineering Research. Frost and Sullivan.

Ginsberg, A. and Venkatraman, N., 1985. Contingency perspectives of organizational strategy: a critical review of the empirical research. Academy of Management Review, 10 (3), 421-434.

Gulati, R., 1999. Network location and learning: the influence of network resources and firm capabilities on alliance formation. Strategic Management Journal, 20, 397-420.

Hamel, G. and Prahalad, C.K., 1989. Strategic intent. Harvard Business Review, 67 (3), 63-76.

Hamel, G. and Valikangas, L., 2003. The quest for resilience. Harvard Business Review, 81 (9), 52-63.

Hobday, M., 1995. East Asian latecomer firms: learning the technology of electronics. World Development, 23 (7), 1171-1193.

Hong, Y. and Choi, T.Y., 2002. Unveiling the structure of supply networks: case studies in Honda, Acura and Daimler Chrysler. Journal of Operations Management, 20, 469-493.

Jensen, M.C. and Ruback, R.S., 1983. The market for corporate control: the scientific evidence. Journal of Financial Economics, 11, 5-50.

Kale, P., Singh, H., and Perlmutter, H., 2000. Learning and protection of proprietary assets in strategic alliances: building relational capital. Strategic Management Journal, 21, 217-237.

Kim, L., 1997. Imitation to innovation: the dynamics of Korea's technological learning. Boston: Harvard Business School Press.

Kita, M., 2001. How the EMS (Electronics Manufacturing Service) business model can help Japanese corporations revolutionize their factories? JBIC Review, 4, 1-24.

Knudsen, M.P. and Servais, P., 2007. Analyzing internationalization configurations of SME's: the purchaser's perspective. Journal of Purchasing and Supply Management, 13 (2), $137-151$.

Leung, A. and Yip, G., 2003. The global OEM: the transformation of Asian supplier companies. In: J. Birkinshaw, et al., eds. The future of multinational companies. Chichester, UK: Wiley, 86-99.

Li, H. and Tan, K., 2004. SMEs business growth model: a medium to big effort. International Journal of Management and Enterprise Development, 1 (3), 195-207.

Lu, J. and Beamish, P.W., 2001. Internationalization and performance of SMEs. Strategic Management Journal, 22 (6/7), 565-586.

Mathews, J.A., 2002. Competitive advantages of latecomer firm: a resource-based account of industrial catch-up strategies. Asia Pacific Journal of Management, 19, 467-488.

McDermott, C.M., 1999. Managing radical product development in large manufacturing firms: a longitudinal study. Journal of Operations Management, 17, 631-644.

McManus, S., et al., 2007. Resilience management: a framework for assessing and improving the resilience of organisations. Resilient Organisations Report 2007/01. R.O.R. Programme.

Melin, L., 1992. Internationalization as a strategy process. Strategic Management Journal, 13 (2), 99-118. 
Meredith, J., 1998. Building operations management theory through case and field research. Journal of Operations Management, 16, 441-454.

Miles, H. and Huberman, M., 1984. Qualitative data analysis: a sourcebook. Beverly Hills, CA: Sage.

Mitroff, I.I. and Alpasan, M.C., 2003. Preparing for the evil. Harvard Business Review, 81 (4), $109-115$.

Paton, D., 1999. Disaster business continuity: promoting staff capability. Disaster Prevention and Management, 8 (2), 127-133.

Pearson, C. and Mitroff, I., 1993. From crisis prone to crisis prepared: a framework for crisis management. Academy of Management Executive, 71, 48-59.

Peng, M.W., 1997. Firm growth in transitional economies: three longitudinal cases from China, 1989-96. Organization Studies, 18 (3), 385-413.

Penrose, E., 1995. The theory of the growth of the firm. 3rd ed. Oxford: Oxford University Press.

Ponomarov, S.Y. and Holcomb, M.C., 2009. Understanding the concept of supply chain resilience. International Journal of Logistics Management, 20 (1), 124-143.

Porter, M., 1990. The competitive advantage of nations. New York: The Free Press.

Prashantham, S., 2008. Local MNC tiles and internationalisation capability in SMEs. Strategic Management Society (SMS) Special India Conference, 12-14 December 2008, Hyderabad.

Prashantham, S. and McNaughton, R.B., 2006. Facilitating links between MNC subsidiaries and SMEs: the Scottish technology and collaboration (STAC) initiative. International Business Review, 15, 447-462.

Reinmoeller, P. and van Baardwijk, N., 2005. The link between diversity and resilience. MIT Sloan Management Review, 46 (4), 61-65.

Riolli, L. and Savicki, V., 2003. Information system organisational resilience. Omega: The International Journal of Management Science, 31, 227-233.

Rutter, M., 1993. Resilience: some conceptual considerations. Journal of Adolescent Health, 14, 626-631.

Salancik, G.R. and Pfeffer, J., 1978. A social information processing approach to job attitudes and task design. Administrative Science Quarterly, 23 (2), 224-253.

Sapienza, H., et al., 2006. A capabilities perspective on the effects of early internationalization on firm survival and growth. Academy of Management Review, 31, 914-933.

Sarkar, M.B., Echambadi, R., and Harrison, J.S., 2001. Alliance entrepreneurship and firm market performance. Strategic Management Journal, 22, 701-711.

Sheffi, Y., 2006. Manage risk through resilience. Chief Executive, 214, 28-29.

Sheffi, Y., 2007. The resilient enterprise: overcoming vulnerability for competitive advantage. Boston, MA: MIT Press.

Sheffi, Y. and Rice, J.B., 2005. A supply chain view of the resilient enterprise. Sloan Management Review, 47 (1), 41-48.

Starr, R., Newfrock, J., and Delurey, M., 2003. Enterprise resilience: managing risk in the networked economy. strategy+business, 30, 1-10.

Voss, C., Tsikriktsis, N., and Frohlich, M., 2002. Case research in operations management. International Journal of Operations and Production Management, 22 (2), 195-219.

Wernerfelt, B., 1984. A resource-based view of the firm. Strategic Management Journal, 5, 171-180.

Yin, R.K., 1994. Case Study Research: Design and Methods. Beverly Hills: Sage.

Zhai, E., Shi, Y., and Gregory, M., 2007. The growth and capability development of electronics manufacturing service (EMS) companies. International Journal of Production Economics, 107, 1-19. 